\title{
Study of the effects of hydraulic fractures on gas and water flow in shale gas reservoirs
}

\section{Yujin Wan, Zhiye Chen, Weijun Shen, Zexi Kuang, Xiaohua Liu, Wei Guo \& Yong $\mathrm{Hu}$}

To cite this article: Yujin Wan, Zhiye Chen, Weijun Shen, Zexi Kuang, Xiaohua Liu, Wei Guo \& Yong Hu (2019): Study of the effects of hydraulic fractures on gas and water flow in shale gas reservoirs, Energy Sources, Part A: Recovery, Utilization, and Environmental Effects, DOI: 10.1080/15567036.2019.1679916

To link to this article: https://doi.org/10.1080/15567036.2019.1679916

册 Published online: 15 Oct 2019.

Submit your article to this journal $\pi$

山 Article views: 14

Q View related articles $\sqsubset$

View Crossmark data $\asymp$ 


\title{
Study of the effects of hydraulic fractures on gas and water flow in shale gas reservoirs
}

\author{
Yujin Wan ${ }^{a}$, Zhiye Chen ${ }^{b}$, Weijun Shen $\mathbb{D D}^{\mathrm{c}}{ }^{\mathrm{d}}$, Zexi Kuang ${ }^{\mathrm{e}}$, Xiaohua Liu ${ }^{\mathrm{a}}$, Wei Guo ${ }^{\mathrm{a}}$, \\ and Yong $\mathrm{Hu}^{\mathrm{a}}$ \\ aPetroChina Research Institute of Petroleum Exploration \& Development, Beijing, China; ${ }^{\text {bPetroleum Engineering }}$ \\ School, Southwest Petroleum University, Chengdu, China; 'Key Laboratory for Mechanics in Fluid Solid Coupling

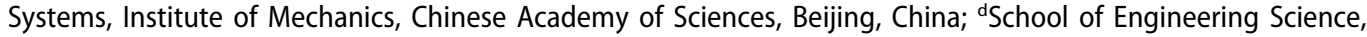

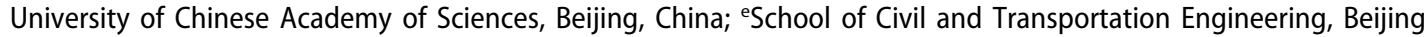 \\ University of Civil Engineering and Architecture, Beijing, China
}

\begin{abstract}
Horizontal drilling and multi-stage hydraulic fracturing are the two key technologies for the successful development of shale gas reservoirs. However, there exist large uncertainties in optimizing hydraulic fracturing which affects water retention into shale matrix and gas productivity. In this work, a basic reservoir model with six-stage hydraulic-fracturing treatment was constructed to understand water retention and gas production in shale gas reservoirs. Gas diffusion, gas desorption, Darcy flow as well as nonDarcy flow were considered in this model. Then, a sensitivity study was performed to investigate the effects of hydraulic fractures on water retention and gas conductivity. The results indicate that only $34 \%$ of the fracturing water could be recovered back to the surface, and most of them remain in shale formations to interfere with gas production. The increase of fracture half-length, fracture width, fracture permeability, and fracture conductivity will reduce water retention while water retention in shale matrix will increase with the increasing of fracture spacing and fracture number. This work can provide a better understanding of the effects of hydraulic fractures on gas and water flow so as to optimize the hydraulic-fracturing treatment in shale gas reservoirs.
\end{abstract}

\section{ARTICLE HISTORY}

Received 4 March 2019

Revised 10 July 2019

Accepted 12 July 2019

\section{KEYWORDS}

Shale gas reservoir; hydraulic fracture; sensitivity analysis; gas desorption; water retention; gas production

\section{Introduction}

In recent years, shale gas has become increasingly an important energy source and attracted considerable public concern (Shen, Zheng, and Oldenburg et al. 2018a; Sutton, Cox, and Barree 2010; Tokunaga et al. 2017). Horizontal drilling and multi-stage hydraulic fracturing are the main technologies for the successful gas production in shale gas reservoirs. During the hydraulicfracturing treatment, larger and highly fractured networks in shale formations were created so that shale gas can flow into the wellbores (Cheng 2012; Yu, Bo, and Sepehrnoori 2014). Despite the success of this technology, the uncertainties associated with the effects of hydraulic fractures require to be understood in order to improve the efficiencies and optimize the hydraulic-fracturing design in shale gas reservoirs. The hydraulic-fracturing process introduces large volumes of water into shale formations, but only a small part of the fracturing water could be recovered back to the surface, most of which remains in shale formations to interfere with gas production (Engelder, Cathles, and Bryndzia 2014; Makhanov et al. 2014; Ren et al. 2018). Therefore, there is greatly significant to

CONTACT Weijun Shen wjshen763@imech.ac.cn 8 Key Laboratory for Mechanics in Fluid Solid Coupling Systems, Institute of Mechanics, Chinese Academy of Sciences, Beijing, 100190, China

This article has been republished with minor changes. These changes do not impact the academic content of the article. Color versions of one or more of the figures in the article can be found online at www.tandfonline.com/ueso. 
understand the effects of hydraulic-fracturing parameters for gas productivity and optimizing the hydraulic-fracturing design in shale gas reservoirs.

Gas shale is a sedimentary rock, which is mainly composed of clay minerals and mixed with quartz, feldspar debris and other chemical substances. Compared with conventional gas reservoirs, shale is characterized by relatively low porosity, ultra-low permeability and high organic content (Guo et al. 2018; Shen et al. 2018b; Shen, Wan, Kim, and Li 2015; Wei et al. 2019; Xu et al. 2018). Thus, the gas flow in shale gas reservoirs is a complex flow process, including the flow with the macro and molecular scale. Some studies have been conducted for shale gas reservoirs in the last decade (King 2010; Perdomo et al. 2010). According to the Knudsen number $\left(K_{n}\right)$, Swami, Clarkson, and Settari (2012) and Shen et al. (2019) divided gas flow in shale gas reservoirs into four regimes, including viscous flow $\left(K_{n} \leq 0.001\right)$, slip flow $\left(0.001 \leq K_{n} \leq 10\right)$, transition flow $\left(0.1 \leq K_{n} \leq 10\right)$ and Knudsen flow $\left(K_{n} \geq 10\right)$. A few researchers assumed that gas diffusion, adsorption and desorption, Darcy and non- Darcy flow exist in shale gas reservoirs (Dahaghi 2010; Dahaghi and Mohaghegh 2011; Javadpour 2009; Ozkan, Brown, Raghavan, and Kazemi 2009), and Moridis, Blasingame, and Freeman (2010) and Freeman, Moridis, and Blasingame (2011) presented a very comprehensive review of flow mechanism in shale gas reservoirs.

Hydraulic fracturing is the process of injecting the fracturing water to create multiple fractures in shale formations, and consequently increases largely the contact areas between the fractures and the reservoirs. The results of field studies have indicated only $10 \%$ to $50 \%$ of the fracturing water could be recovered, most of which was trapped in the shale matrix near the fracture face due to high capillary pressure (King 2010; Shen, Xu, Li, Huang, and Gu 2016). The hydraulic-fracturing design is of great importance, which directly affects water retention, gas productivity and operating costs (Kaiser 2012). Some previous studies have focused on optimizing the fracturing treatment for shale gas reservoirs in recent years. Cipolla et al. (2008) and Yu and Sepehrnoori $(2013,2015)$ successively studied the effects of fracturing parameters (such as fracturing spacing, fracture half-length, and fracture conductivity) on gas production performance in shale formations. Mayerhofer, Lolon, Warpinski, Cipolla, Walser, and Rightmire (2010) proposed that a large stimulated reservoir volume with small fracture spacing was in favor of gas productivity. And some flow mechanisms such as imbibition dominated by capillary pressure, relative permeability and stress-sensitive fracture conductivities (Arshadi, 2018; Bimal and Sharma 2004; Cheng 2012; Holditch 1978; Kamath and Laroche 2003; Le, Hai, and Mahadevan 2009; Li, Guo, and Hu et al. 2018; Ren et al. 2018) affecting water and gas flow have been conducted in shale formations. However, most of these studies were mainly concentrated in gas performance, which did not relate to water retention in shale formations. In addition, the gas and water flow in shale gas reservoirs are not fully considered and the effects of hydraulic-fracturing parameters are not systematically studied. Therefore, it is extremely necessary to understand the effects of these hydraulic-fracturing parameters on water retention and gas productivity so as to optimize the fracturing treatment for shale gas reservoirs.

In this study, a basic reservoir model with six-stage hydraulic-fracturing treatment was constructed to understand water retention and gas production using the GEM module of Computer Modeling Group (CMG) (CMG: GEM user's guide 2012). Gas diffusion, gas isotherm desorption, Darcy flow as well as non-Darcy flow were considered in the model. The process of water retention and gas production was analyzed and discussed. Then, a series of sensitivity analysis to quantify the effects of hydraulic-fracturing parameters on water retention and gas productivity, such as fracture spacing, fracture half-length, fracture width, fracture permeability, fracture conductivity, and fracture number, were performed to understand water retention and gas flow in shale gas reservoirs.

\section{Shale gas reservoir modeling}

Gas shale is characterized by complex pore structures, ultra-low permeability and various storages (Liu et al. 2017; Shen et al. 2018b). Consequently, there is a great challenge to accurately understand gas and water flow in hydraulically fractured shale gas reservoirs due to the complexities of hydraulic 
fractures created and the uncertainties associated with fluid transport processes. The reservoir simulation, as a preferred method, can be used to understand gas and water flow performance. In this study, a numerical reservoir simulator of the CMG-GEM module was applied to simulate the multiple hydraulic-fracturing treatment and understand gas and water flow in shale gas reservoirs. In the model, a hydraulic fracture was considered as perforation for every cluster within every fracture stage, and the fractures were assumed to be spaced and equal in length. Due to the hydraulicfracturing treatment, there exists gas-water two-phase flow in shale gas reservoirs. Thus, the dual permeability model is used to study the gas and water flow in hydraulically fractured shale gas reservoirs (Shen, $\mathrm{Xu}, \mathrm{Li}$, Huang, and $\mathrm{Gu} 2016$ ), and the fluid flow equation of a dual permeability model can be described as,

$$
\begin{gathered}
\left(\emptyset^{m} S_{\beta}^{m} \rho_{\beta}^{m}+v_{s g}\right)+\nabla \cdot\left(\rho_{\beta}^{m} v_{\beta}^{m}\right)+q_{\beta}^{m f}+q_{\beta}^{m}=0 \\
\frac{\partial}{\partial t}\left(\emptyset f S_{\beta}^{f} \rho_{\beta}^{f}\right)+\nabla \cdot\left(\rho_{\beta}^{f} v_{\beta}^{f}\right)-q_{\beta}^{m f}+q_{\beta}^{f}=0
\end{gathered}
$$

where the superscripts $m$ and $f$ represent the matrix and the fracture, respectively; the subscript $\beta$ represents the phase $\left(\beta=g\right.$ for gas and $\beta=w$ for water); $\emptyset$ is the effective porosity; $S_{\beta}$ is the saturation of the phase $\beta$; $\rho_{\beta}$ is the density of the phase $\beta$; $v_{s g}$ is the gas adsorption or desorption term; $v_{\beta}$ is the volumetric velocity vector of the phase $\beta ; q_{\beta}^{m f}$ is the exchange term between the matrix and the fracture; $q_{\beta}$ is the sink or source term of the phase $\beta$ per unit volume of formation.

In the simulation, the local grid refinement (LGR) with logarithmic cell spacing was used in hydraulic fractures, which could accurately simulate gas flow from shale matrix to hydraulic fractures, i.e., properly incorporate the transient flow from shale matrix to shale fractures $(\mathrm{Yu}$ and Sepehrnoori 2013; Yu et al. 2015). In addition, a dual permeability grid was employed in the model, which allowed the simultaneous fracture-fracture and matrix-matrix flow. And it could efficiently and accurately simulate the transient gas production in shale gas reservoirs (Cipolla et al. 2010; Rubin 2010). Besides, the reservoir was considered to be homogeneous, and there was no stress dependent in porosity and permeability.

Compared with conventional gas reservoirs, the gas flow in shale formations is more complicated, which includes gas diffusion and desorption from shale matrix to shale fracture, Darcy flow in natural fractures and non-Darcy flow in hydraulic fractures (Moridis, Blasingame, and Freeman 2010). In this study, gas diffusion flow is considered with the diffusion coefficient from shale matrix to the fracture. The classical Langmuir isotherm with Langmuir pressure and Langmuir volume is used to simulate gas desorption in shale matrix (Heller and Zoback 2014; Langmuir 1916). The Langmuir isotherm can be expressed as

$$
v_{s g}=v_{L} \frac{p}{p+p_{L}}
$$

where $v_{s g}$ is the adsorption mass; $v_{L}$ is the Langmuir volume; $p$ is the gas reservoir pressure; $p_{L}$ is the Langmuir pressure.

After the hydraulic-fracturing treatment, there exists high flow velocity in the stimulated reservoir volume, which should be simulated as non-Darcy flow (Freeman, Moridis, and Blasingame 2011; Moridis, Blasingame, and Freeman 2010). The non-Darcy flow can be described by the Forchheimer modification to Darcy Law which is given below,

$$
-\nabla p=\frac{\mu}{k} v+\beta \rho v^{2}
$$

where $\nabla p$ is the pressure gradient vector; $\mu$ is the viscosity; $k$ is the permeability; $v$ is the velocity; $\rho$ is the phase density; $\beta$ is the non-Darcy Beta factor. 


\section{Case study}

In this study, a horizontal well with a lateral length of $1000 \mathrm{~m}$ is considered in this model, and the dimension of shale gas reservoir model is $1100 \mathrm{~m}$ (length) $\times 900 \mathrm{~m}$ (width) $\times 60 \mathrm{~m}$ (height) with 10 layers, as shown in Figure 1a. There exist two wells, which includes an injector and a producer, and it is stimulated with a six-stage hydraulic-fracturing treatment illustrated in Figure $1 \mathrm{~b}$. In each single stage, the fracture half-length is $130 \mathrm{~m}$, and the fracture space is set as $100 \mathrm{~m}$. A local grid refinement with logarithmic cell spacing of $9 \times 9 \times 1$ is used in the hydraulic-fracturing treatment. The parameters of shale gas reservoirs and fractures are used for the simulation study, as listed in Table 1. Two different sets of relative permeability curves are used to describe water and gas flow in shale matrix and fractures, respectively, which is illustrated in Figure 2a. The cure of capillary pressure is used in the matrix, as shown in Figure $2 \mathrm{~b}$. As a result of the larger permeability in fractures, the capillary pressure in fractures is set as zero. During the stimulated process, the injector is used to simulate the hydraulic-fracturing treatment, the injection rate of which is $1000 \mathrm{~m}^{3} /$ day for 2 days. Then, the producer produces for 5000 days with a maximum gas rate of $1.0 \times 10^{5} \mathrm{~m}^{3} /$ day

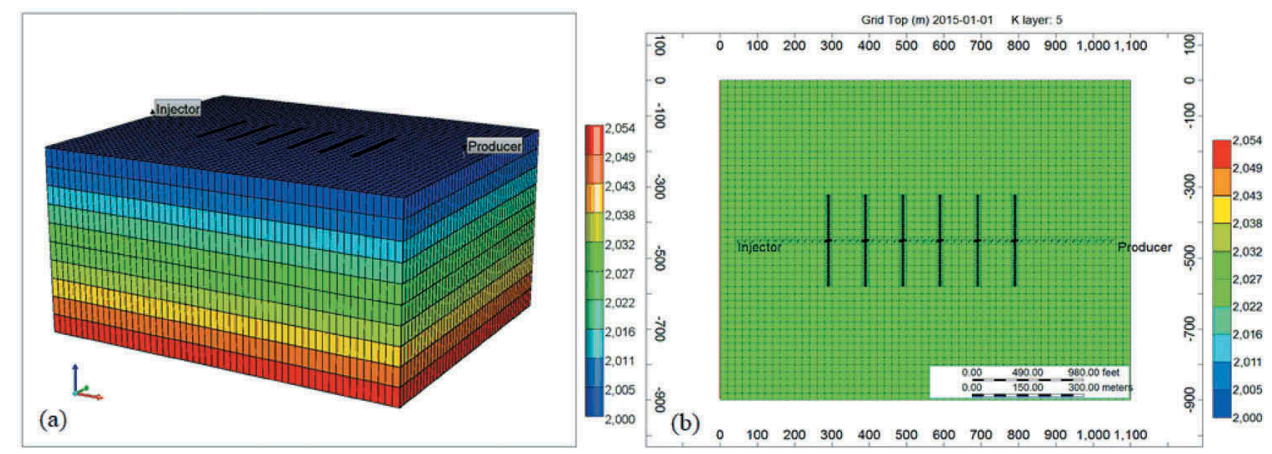

Figure 1. A basic case model with six stages of hydraulic fracture.

Table 1. Parameters of the numerical reservoir model used in the study.

\begin{tabular}{lcc}
\hline Parameter & Value & Unit \\
\hline Model dimension $(\mathrm{L} \times \mathrm{W} \times \mathrm{H})$ & $1100 \times 900 \times 60$ & $\mathrm{~m}$ \\
Initial reservoir pressure & 25 & $\mathrm{MPa}$ \\
Bottom-hole pressure & 1 & $\mathrm{MPa}$ \\
Initial reservoir temperature & 70 & ${ }^{\circ} \mathrm{C}$ \\
Reservoir depth & 2000 & $\mathrm{~m}$ \\
Rock density & 2500 & $\mathrm{~kg} / \mathrm{sm}^{3}$ \\
Rock compressibility & $4.0 \times 10^{-6}$ & $\mathrm{kPa}^{-1}$ \\
Initial gas saturation & 0.75 & $\mathrm{Value}^{2}$ \\
Gas diffusivity & 0.0006 & $\mathrm{~cm}^{2} / \mathrm{s}$ \\
Matrix porosity & 0.06 & $\mathrm{Value}$ \\
Matrix permeability & 0.0001 & $\mathrm{mD}$ \\
Fracture porosity & 0.001 & $\mathrm{Value}$ \\
Fracture permeability & 0.01 & $\mathrm{mD}$ \\
Injection rate & $1.0 \times 10^{3}$ & $\mathrm{~m}^{3} / \mathrm{day}$ \\
Gas rate (max) & $1.0 \times 10^{5}$ & $\mathrm{~m} / \mathrm{day}$ \\
Horizontal well length & 1000 & $\mathrm{~m}$ \\
Fracture height & 60 & $\mathrm{~m}$ \\
Fracture conductivity & 167 & $\mathrm{mD} \mathrm{m}$ \\
Fracture half length & 130 & $\mathrm{~m}$ \\
Fracture spacing & 100 & $\mathrm{~m}$ \\
Langmuir pressure & 1.6 & $\mathrm{MPa}$ \\
Langmuir volume & 0.09 & $\mathrm{~mol} / \mathrm{kg}$ \\
\hline
\end{tabular}



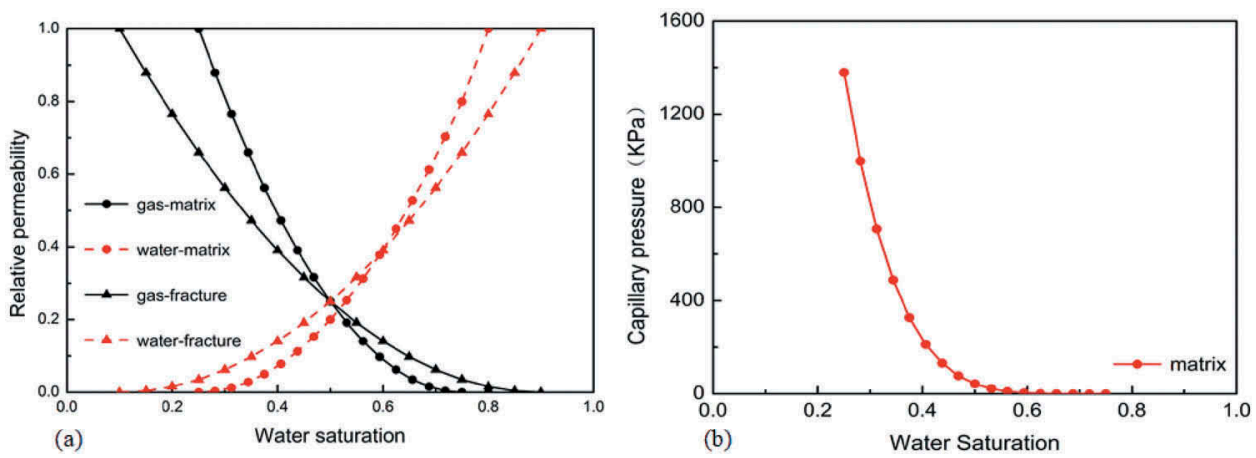

Figure 2. Two different sets of relative permeability curves (a) and capillary pressure (b) in shale matrix.

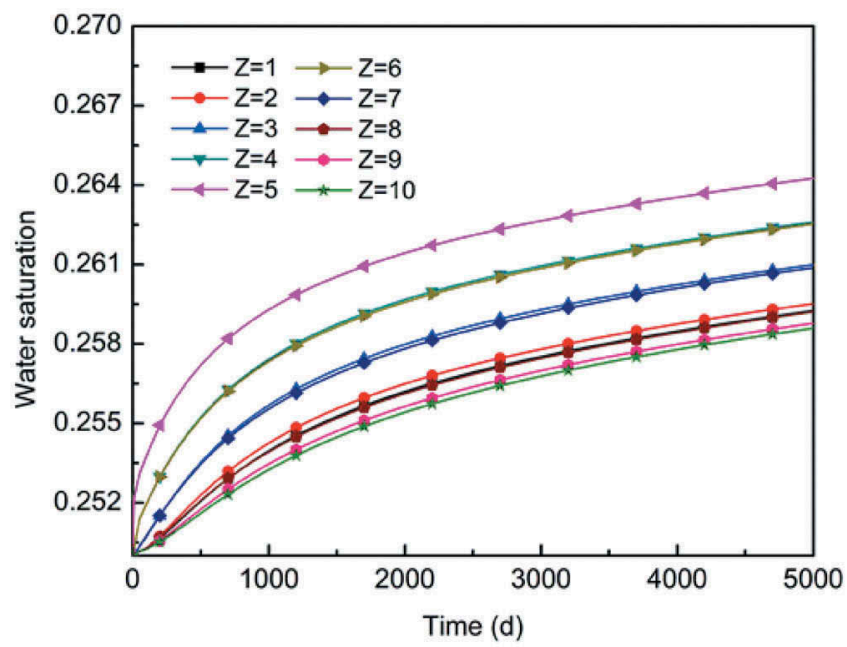

Figure 3. Variation of water saturation inside shale matrix with different layers versus time.

while the injector is closed. During the period of gas production, the bottom-hole pressure is set at $1.0 \mathrm{MPa}$.

Figure 3 shows the curves of water saturation inside shale matrix with depths versus time. From the result of Figure 3, it is seen that the retained water distributes along the sides of hydraulic position. The water saturation of horizontal well location is bigger than other layers in the reservoirs. It implies that most of the fracturing water remains near the horizontal well, and then flows along the sides of the well. Thus, it is significant to deal with the fracturing water after the hydraulic-fracturing treatment and consequently reduce water retention in shale formations. The variation of water and gas saturation at the bottom and top inside shale matrix versus time is illustrated in Figure 4. From the result of Figure 4, it is observed that water saturation inside shale matrix increases and gas saturation decreases during gas production, which indicates the fracturing water flows into shale matrix. The gas rate in production increases and then decreases, but it is far less than the maximum gas rate. The reason is that the retained fracturing water influences the increase of gas rate. In addition, we can see that the cumulative water production is $687 \mathrm{~m}^{3}$ at the end of a 5000-day periods as shown in Figure 5, and it means that only $34 \%$ of the fracturing water $\left(2000 \mathrm{~m}^{3}\right)$ can be recovered back to the surface during the gas production process. The remaining water is still trapped in shale formations to interfere with gas production. Some 


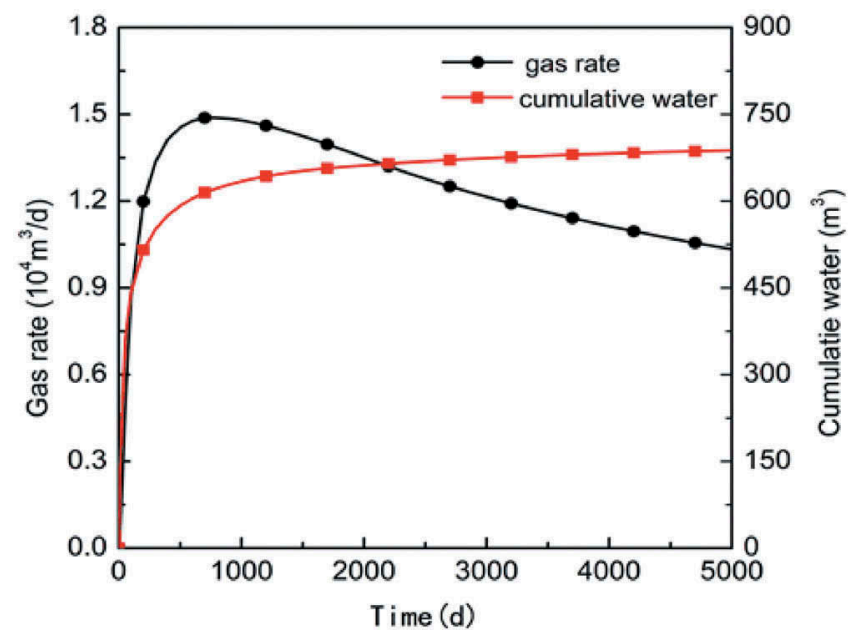

Figure 4. Variation of gas rate and cumulative water versus time.
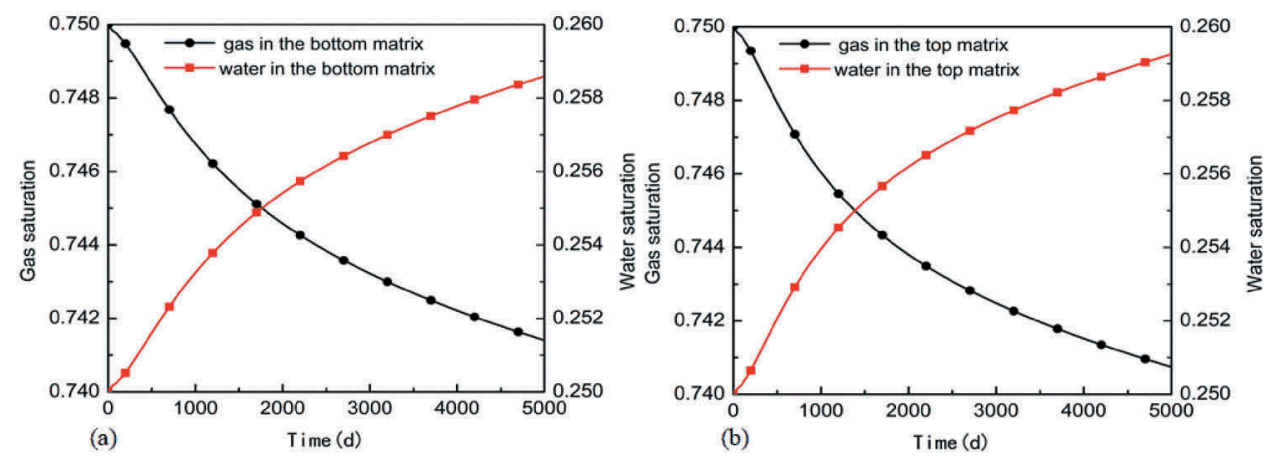

Figure 5. Variation of water (a) and gas (b) saturation inside matrix versus time.

results of field data have indicated that less than $50 \%$ of the injected fracturing water can be recovered (King 2010), most of which remains in shale formations and consequently reduces gas production.

\section{Sensitivity analysis}

\section{Effect of the fracture spacing}

In order to achieve economic production rate and an optimum depletion of gas reservoirs, there is greatly significant to minimize the spacing between the fractures (Cipolla et al. 2010). During the hydraulic-fracturing treatment, the fracture spacing determines the number of hydraulic fractures along the horizontal wellbore. The effects of the hydraulic fracture spacing from $80 \mathrm{~m}$ to $160 \mathrm{~m}$ on water retention and gas production have been conducted in this study. Figure 6 shows the variation of water saturation inside matrix (a) and gas rate (b) versus time. From the result of Figure 6, it can be seen that the fracture spacing affects water retention and gas production in shale gas reservoirs. With the fracture spacing increasing, water saturation inside shale matrix increases. At the early production time, gas rate increases linearly, and then decreases with the increasing of fracture spacing. The reason is that water retention in shale matrix inhibits gas production. Thus, the 

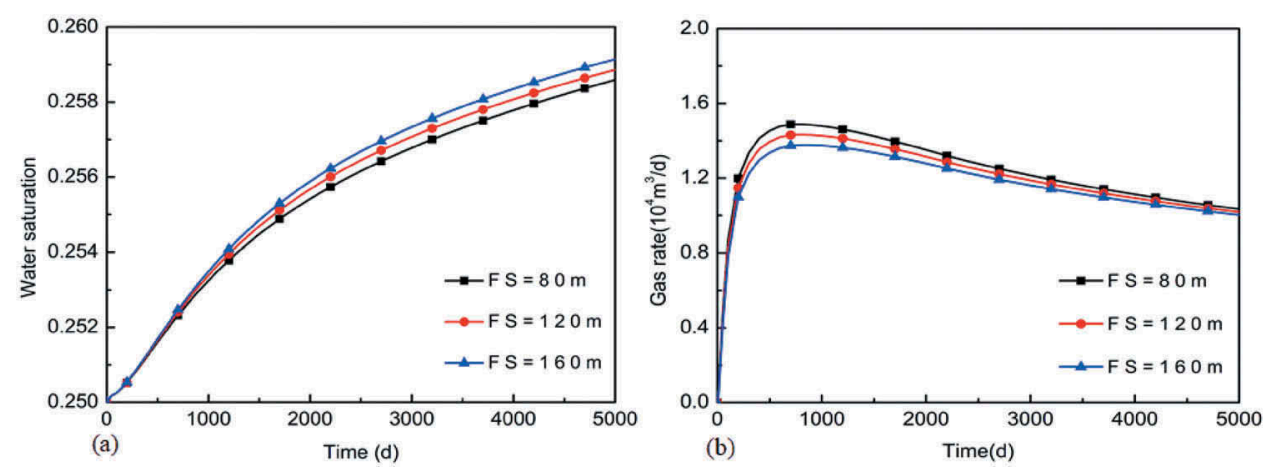

Figure 6. Variation of water saturation inside matrix (a) and gas rate (b) versus time for fracturing spacing.

reasonable fracturing spacing is crucial in the development of shale gas reservoirs and the infinitely increasing fracture spacing may disfavor the fracturing water recover and gas production.

\section{Effect of the fracture half-length}

The fracture half-length is the horizontal distance from hydraulic fractures to the horizontal wellbore, which affects gas and water flow in shale reservoirs. The values of the fracture half-length between $100 \mathrm{~m}$ and $200 \mathrm{~m}$ are conducted to investigate water retention and gas production. The variation of water saturation inside matrix (a) and gas rate (b) versus time is illustrated in Figure 7. From the result of Figure $7 \mathrm{a}$, we can see that the water saturation inside shale matrix decreases with the increase of fracture half-length. As shown in Figure $7 \mathrm{~b}$, the bigger the fracture half-length is, and the higher the gas rate is. This is due to the increasing fracture half-length which expands the drainage area, and consequently, it favors gas production.

\section{Effect of the fracture width}

The fracture width is an important parameter in the hydraulic-fracturing process, which affects the fracture conductivity in shale gas reservoirs. In this study, the values of hydraulic fracture width from $0.001 \mathrm{~m}$ to $0.01 \mathrm{~m}$ are selected to understand water retention and gas production in shale gas reservoirs. Figure 8 presents the variation of water saturation inside matrix (a) and gas rate (b) versus time. From the result of Figure 8, it can be seen that the water saturation inside shale matrix decreases with the increase of the fracture width. At the early production time, there is no change of


Figure 7. Variation of water saturation inside matrix (a) and gas rate (b) versus time for fracture half-length. 

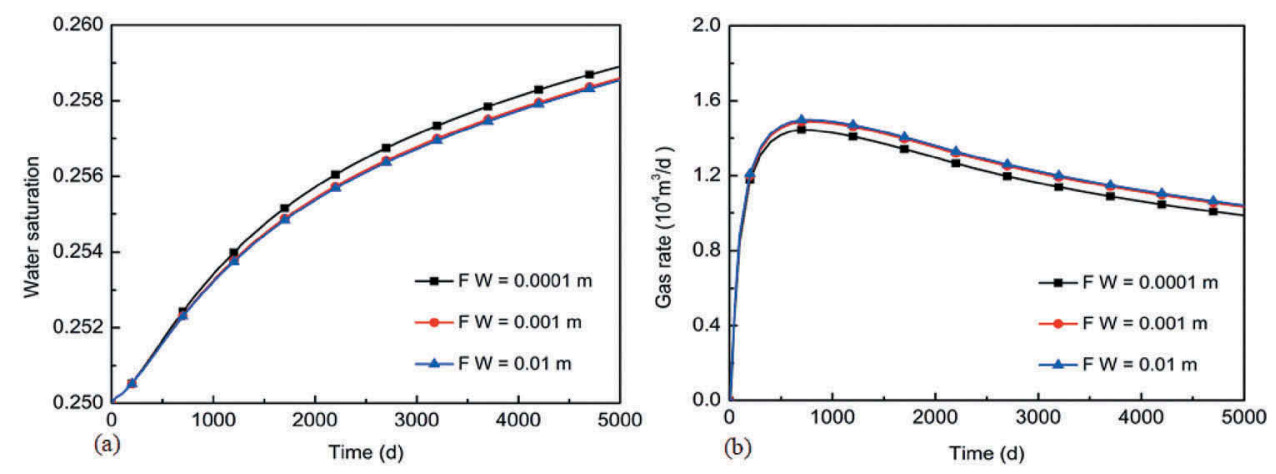

Figure 8. Variation of water saturation inside matrix (a) and gas rate (b) versus time for fracture width.

gas rate with the fracture width increasing. But it will increase with the increasing of fracture width in the later production. It suggests that the increasing fracture width will favor the fracturing water flow back to the surface and gas production, but it is noted that there is little change when the fracture width exceeds $0.001 \mathrm{~m}$.

\section{Effect of the fracture permeability}

Permeability is a property of the reservoir rock that measures the capacity and ability of the formation to transmit fluid (Ahmed 2010). The permeability of hydraulic fracturing directly affects gas and water flow in the stimulated reservoir volume. The values of the fracture permeability between $2000 \mathrm{mD}$ and $8000 \mathrm{mD}$ are considered in this simulation. Figure 9 shows the variation of water saturation inside matrix (a) and gas rate (b) versus time. From the result of Figure 9a, with the fracture permeability increasing water saturation in shale matrix decreases. It indicates the increasing fracture permeability favors the fracturing water flow back to the surface. As illustrated in Figure 9b, the bigger the fracture permeability is, and the bigger the gas rate is. The reason is that the bigger fracture permeability can favor gas flow from shale matrix. Thus, the fracture permeability directly affects water retention in shale formations and gas production in shale gas reservoirs.

\section{Effect of the fracture conductivity}

The hydraulic fracture conductivity is defined as the values of fracture permeability multiplied by fracture width, which is a significant parameter to evaluate the effects of hydraulic fracturing
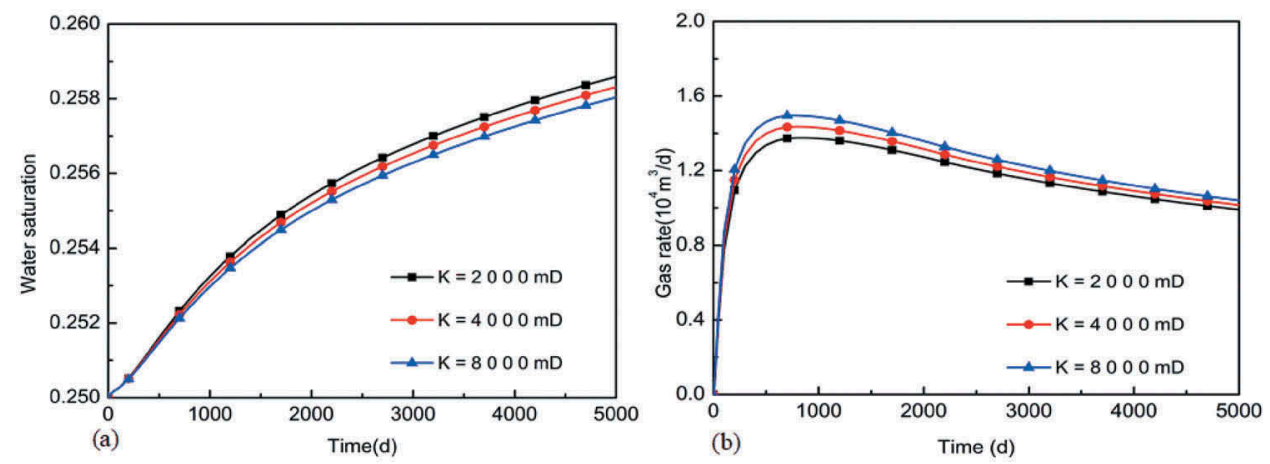

Figure 9. Variation of water saturation inside matrix (a) and gas rate (b) versus time for fracture permeability. 

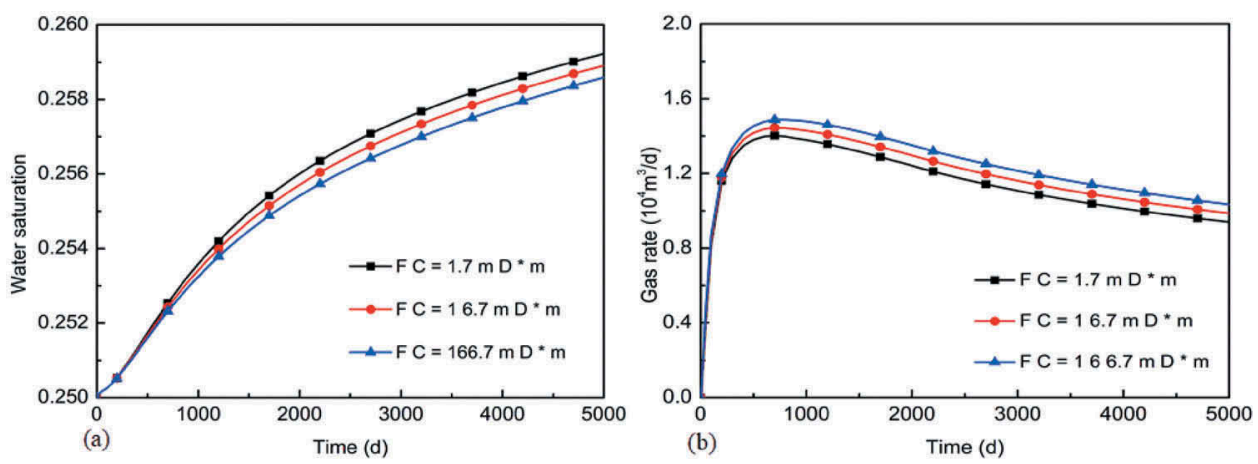

Figure 10. Variation of water saturation inside matrix (a) and gas rate (b) versus time for fracture conductivity.

(Ahmed 2010). The effects of hydraulic fracture conductivity from $1.7 \mathrm{mD} \cdot \mathrm{m}$ to $166.7 \mathrm{mD} \cdot \mathrm{m}$ are chosen to study water retention and gas production in shale gas reservoirs. The variation of water saturation inside matrix (a) and gas rate (b) versus time is illustrated in Figure 10. From the result of Figure 10a, it can be seen that the water saturation inside matrix decreases with the increase of hydraulic fracture conductivity. It suggests the increasing fracture conductivity will inhibit water retention in shale gas reservoirs. From Figure 10b, gas rate increases with the fracture conductivity increasing, and the reason is that the less water retention promotes gas production. Therefore, the increasing fracture conductivity favors the fracturing water recovery and gas production.

\section{Effect of the fracture number}

The fracture number is the number of the hydraulic-fracturing stage in shale gas reservoirs. The more the number is, and the larger the stimulated volume is. The values of the hydraulic fracture number between 6 and 10 are conducted to study water and gas flow in shale gas reservoirs. Figure 11 illustrates the variation of water saturation inside matrix (a) and gas rate (b) over time. From the result of Figure 11a, we can see that water saturation in shale matrix increases with the fracture number increasing. It means that the increase of hydraulic fracture number will disfavor the fracturing water flow back to the surface, which increases water retention in hydraulic fracturing. As illustrated in Figure 11b, there seems little change in the early production time, and the gas rate increases linearly. But the gas rate then decreases with the increasing of fracture number. Consequently, it is necessary to appropriately increase fracture number so as to decrease water retention and favor gas production.
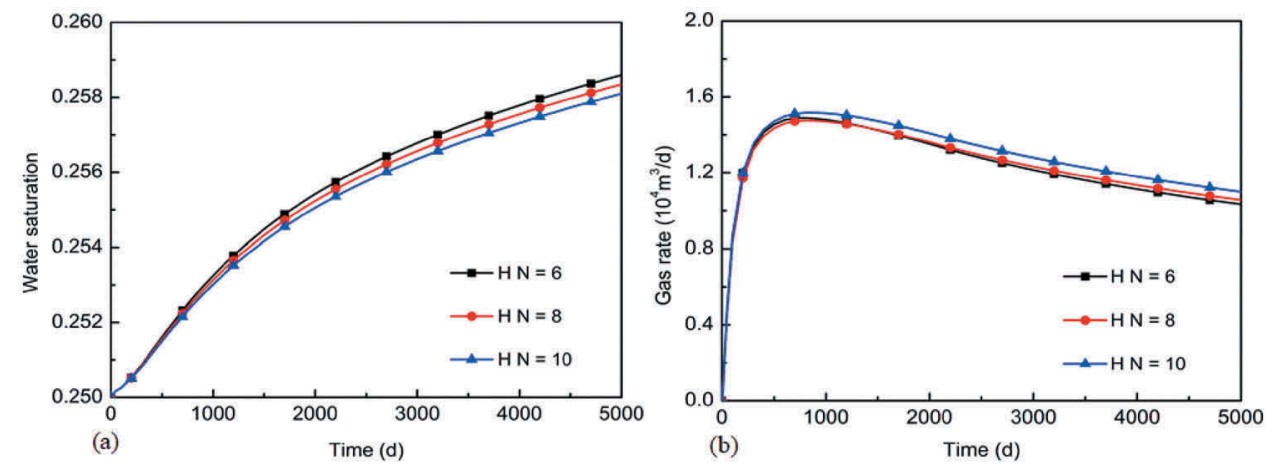

Figure 11. Variation of water saturation inside matrix (a) and gas rate (b) versus time for fracture number. 


\section{Conclusions}

In this study, a horizontal well with six-stage hydraulic-fracturing treatment was constructed to understand water retention and gas production in shale gas reservoirs. Gas diffusion and Langmuir isotherm desorption from shale matrix to shale fracture, Darcy flow in natural fracture and nonDarcy flow in hydraulic fractures, were considered in the model. According to the above results, the following conclusions can be drawn: (1) $34 \%$ of the fracturing water can be recovered back to the surface, and most of them remain in shale matrix to interfere with gas production, which is consistent with the field result. Consequently, there is greatly significant to deal with the fracturing water after the hydraulic-fracturing treatment and reduce water retention so as to enhance gas production. (2) With the increasing fracture spacing and fracture number, the fracturing water retained in shale matrix will increase, and consequently, reduce gas production. Thus, the increase of fracture spacing and fracture number goes against the fracturing water go back. (3) With fracture half-length, fracture width fracture permeability and fracture conductivity increasing, the fracturing water retained in shale matrix will decrease and favor gas production in shale gas reservoirs. So there is a necessity to increase fracture half-length, fracture permeability, and fracture conductivity during the hydraulic-fracturing treatment so as to favor gas productivity in shale gas production.

\section{Acknowledgments}

This work was supported by the National Natural Science Foundation of China (No. 11802312 and No. U1762216) and by Open Fund (PLN201810) of State Key Laboratory of Oil and Gas Reservoir Geology and Exploitation (Southwest Petroleum University). We also thank the support from the Youth Foundation of Key Laboratory for Mechanics in Fluid Solid Coupling Systems, Chinese Academy of Sciences.

\section{Funding}

This work was supported by the National Natural Science Foundation of China [No. 11802312 and No. U1762216]; Open Fund of State Key Laboratory of Oil and Gas Reservoir Geology and Exploitation (Southwest Petroleum University) [PLN201810].

\section{Notes on contributors}

Yujin Wan is a senior engineer of full professor at PetroChina Research Institute of Petroleum Exploration \& Development, Beijing, China. His research focused on reservoir characterization, gas reservoir engineering and numerical simulation in reservoirs.

Zhiye Chen is a senior student at Petroleum Engineering School, Southwest Petroleum University, Chengdu, China, and her major is petroleum engineering.

Weijun Shen is an associate professor at Institute of Mechanics, Chinese Academy of Sciences (CAS), Beijing, China. He has over 9 years research experience on reservoir characterization, fluid flow and transport, numerical calculation and simulation in reservoirs, and published over 40 journal papers, book chapters and peer-reviewed conference papers on the related fields.

Zexi Kuang is a senior student at School of Civil and Transportation Engineering, Beijing University of Civil Engineering and Architecture, Beijing, China, and his major is civil engineering.

Xiaohua Liu is a senior engineer at PetroChina Research Institute of Petroleum Exploration \& Development, Beijing, China. Her research focused on gas reservoir engineering and numerical simulation in reservoirs.

Wei Guois a senior engineer at PetroChina Research Institute of Petroleum Exploration \& Development, Beijing, China. Her research focused on gas reservoir engineering and numerical simulation in reservoirs.

Yong $\mathbf{H u}$ is a senior engineer at PetroChina Research Institute of Petroleum Exploration \& Development, Beijing, China. His research focused on fluid flow in gas reservoirs and physical simulation in reservoirs. 


\section{ORCID}

Weijun Shen (D) http://orcid.org/0000-0003-3658-8670

\section{References}

Ahmed, T. 2010. Reservoir engineering handbook. 4th ed. Oxford: Gulf Professional Publishing, Elsevier.

Arshadi, M., M. Piri, and M. Sayed. 2018. Proppant-packed fractures in shale gas reservoirs: An in-situ investigation of deformation, wettability, and multiphase flow effects. Journal of Natural Gas Science and Engineering 59:387-405. doi:10.1016/j.jngse.2018.09.015.

Bimal, P., and M. Sharma. 2004. Cleanup of water blocks in depleted low-permeability reservoirs. SPE Annual Technical Conference and Exhibition, Houston, Texas, September 26-29.

Cheng, Y. 2012. Impact of water dynamics in fractures on the performance of hydraulically fractured wells in gas shale reservoirs. Journal of Canadian Petroleum Technology 51 (2):143-51. doi:10.2118/127863-PA.

Cipolla, C. L., E. P. Lolon, J. C. Erdle, and B. Rubin. 2010. Reservoir modeling in shale-gas reservoirs. SPE Reservoir Evaluation \& Engineering 13 (4):848-54. doi:10.2118/125530-PA.

Cipolla, C. L., N. R. Warpinski, M. J. Mayerhofer, E. P. Lolon, and M. C. Vincent. 2008. The relationship between fracture complexity, reservoir properties, and fracture treatment design. SPE Production \& Operations 25 (4):438-52. doi:10.2118/115769-PA.

CMG: GEM user's guide. 2012. Computer modeling group Ltd. Doi:10.1094/PDIS-11-11-0999-PDN.

Dahaghi, A. K. 2010. Reservoir modeling of New Albany Shale. PhD, West Virginia University.

Dahaghi, A. K., and S. D. Mohaghegh. 2011. A new practical approach in modelling and simulation of shale gas reservoirs: Application to New Albany Shale. International Journal of Oil Gas \& Coal Technology 4 (4):104-33. doi:10.1504/IJOGCT.2011.038925.

Engelder, T., L. M. Cathles, and L. T. Bryndzia. 2014. The fate of residual treatment water in gas shale. Journal of Unconventional Oil \& Gas Resources 7:33-48. doi:10.1016/j.juogr.2014.03.002.

Freeman, C. M., G. J. Moridis, and T. A. Blasingame. 2011. A numerical study of microscale flow behavior in tight gas and shale gas reservoir systems. Transport in Porous Media 90:253-68. doi:10.1007/s11242-011-9761-6.

Guo, W., W. J. Shen, S. W. Zhou, H. Q. Xue, D. X. Liu, and N. Wang. 2018. Shale favorable area optimization in coal-bearing series: A case study from the Shanxi formation in northern Ordos Basin, China. Energy Exploration \& Exploitation 36 (5):1295-309. doi:10.1177/0144598717748951.

Heller, R., and M. Zoback. 2014. Adsorption of methane and carbon dioxide on gas shale and pure mineral samples. Journal of Unconventional Oil \& Gas Resources 8:14-24. doi:10.1016/j.juogr.2014.06.001.

Holditch. 1978. Factors affecting water blocking and gas flow from hydraulically fractured gas wells. Journal of Petroleum Technology 31(12):1515-24. doi:10.2118/7561-PA.

Javadpour, F. 2009. Nanopores and apparent permeability of gas flow in mudrocks (shales and siltstone). Journal of Canadian Petroleum Technology 48 (8):16-21. doi:10.2118/09-08-16-DA.

Kaiser, M. J. 2012. Haynesville shale play economic analysis. Journal of Petroleum Science \& Engineering 82-83 (2):75-89. doi:10.1016/j.petrol.2011.12.029.

Kamath, J., and C. Laroche. 2003. Laboratory-based evaluation of gas well deliverability loss caused by water blocking. SPE Journal 8 (1):71-80. doi:10.2118/83659-PA.

King, G. E. 2010. Thirty years of gas shale fracturing: What have we learned? SPE Annual Technical Conference and Exhibition, Florence, Italy, September 19-22.

Langmuir, I. 1916. The constitution and fundamental properties of solids and liquids. Journal of the American Chemical Society 38 (11):2221-95. doi:10.1021/ja02268a002.

Le, D. H., N. H. Hai, and J. Mahadevan. 2009. Impact of capillary suction on fracture face skin evolution in waterblocked wells. SPE Hydraulic Fracturing Technology Conference, Woodlands, Texas, January 19-21.

Li, X. Z., Z. H. Guo, Y. Hu, et al. 2018. Efficient development strategies for large ultra-deep structural gas fields in China. Petroleum Exploration and Development 45(1):118-26. doi:10.1016/S1876-3804(18)30011-9.

Liu, J. W., P. C. Li, Z. Y. Sun, Z. W. Lu, Z. H. Du, H. B. Liang, and D. T. Lu. 2017. A new method for analysis of dual pore size distributions in shale using nitrogen adsorption measurements. Fuel 210:446-54. doi:10.1016/j. fuel.2017.08.067.

Makhanov, K., A. Habibi, H. Dehghanpour, and E. Kuru. 2014. Liquid uptake of gas shales: A workflow to estimate water loss during shut-in periods after fracturing operations. Journal of Unconventional Oil \& Gas Resources 7 (7):22-32. doi:10.1016/j.juogr.2014.04.001.

Mayerhofer, M. J., E. Lolon, N. R. Warpinski, C. L., Cipolla, D. W., Walser, and C. M, Rightmire. 2010. What is stimulated reservoir volume? SPE Production \& Operations 25(1):89-98. doi:10.2118/119890-PA.

Moridis, G. J., T. A. Blasingame, and C. M. Freeman. 2010. Analysis of mechanisms of flow in fractured tight gas and shale gas reservoirs. SPE Latin American and Caribbean Petroleum Engineering Conference, Lima, Peru, December 1-3. 
Ozkan, E., M. Brown, R. Raghavan, H. Kazemi. 2009. Comparison of fractured horizontal-well performance in conventional and unconventional reservoirs. SPE Reservoir Evaluation \& Engineering 14(2):248-59. doi:10.2118/ 121290-PA.

Perdomo, J. F. A., F. ivan, D. Devegowda, and R. F. Sigal. 2010. Accurate simulation of shale-gas reservoirs. SPE Annual Technical Conference and Exhibition, Florence, Italy, September 19-22.

Ren, L., R. Lin, J. Z. Zhao, V. Rasouli, J. Y. Zhao, and H. Yang. 2018. Stimulated reservoir volume estimation for shale gas fracturing: Mechanism and modeling approach. Journal of Petroleum Science and Engineering 166:290-304. doi:10.1016/j.petrol.2018.03.041.

Rubin, B. 2010. Accurate simulation of non-darcy flow in stimulated fractured shale reservoirs. SPE Western Regional Meeting, Anaheim, California, May 27-29.

Shen, W. J., X. Z. Li, X. B. Lu, W. Guo, S. W. Zhou, and Y. J. Wan. 2018b. Experimental study and isotherm models of water vapor adsorption in shale rocks. Journal of Natural Gas Science and Engineering 52:484-91. doi:10.1016/j. jngse.2018.02.002.

Shen, W. J., F. Q. Song, X. Hu, G. M. Zhu, and W. Y. Zhu. 2019. Experimental study on flow characteristics of gas transport in micro- and nanoscale pores. Scientific Reports 9:10196. doi:10.1038/s41598-019-46430-2.

Shen, W. J., J. M. Wan, Y. Kim, X. Z. Li. 2015. Porosity calculation, pore size distribution and mineral analysis within shale rocks: Application of scanning electron microscopy. Electronic Journal of Geotechnical Engineering 20:11477-90.

Shen, W. J., Y. M. Xu, X. Z. Li, W. Huang, J., Gu. 2016. Numerical simulation of gas and water flow mechanism in hydraulically fractured shale gas reservoirs. Journal of Natural Gas Science \& Engineering 35:726-35. doi:10.1016/j. jngse.2016.08.078.

Shen, W. J., L. G. Zheng, C. M. Oldenburg, et al. 2018a. Methane adsorption and diffusion in shale rocks: A numerical study using the dusty gas model in Tough2/EOS7C-ECBM. Transport in Porous Media 123(3):521-31. doi:10.1007/ s11242-017-0985-y.

Sutton, R. P., S. A. Cox, and R. D. Barree 2010. Shale gas plays: A performance perspective. SPE Tight Gas Completions Conference, San Antonio, Texas, November 2-3.

Swami, V., C. R. Clarkson, and A. Settari 2012. Non-darcy flow in shale nanopores: Do we have a final answer? SPE Canadian Unconventional Resources Conference, Calgary, Alberta, October 30-November 1. doi 10.1094/PDIS-1111-0999-PDN.

Tokunaga, T. K., W. J. Shen, J. M. Wan, Y. Kim, A. Cihan, Y. Q. Zhang, and S. Finsterle. 2017. Water saturation relations and their diffusion-limited equilibration in gas shale: Implications for gas flow in unconventional reservoirs. Water Resources Research 53:9757-70. doi:10.1002/2017WR021153.

Wei, M. Q., Y. G. Duan, M. Z. Dong, Q. T. Fang, and M. Dejam. 2019. Transient production decline behavior analysis for a multi-fractured horizontal well with discrete fracture networks in shale gas reservoirs. Journal of Porous Media 22 (3):343-61. doi:10.1615/JPorMedia.v22.i3.

Xu, C. Y., P. C. Li, Z. W. Lu, J. W. Liu, and D. T. Lu. 2018. Discrete fracture modeling of shale gas flow considering rock deformation. Journal of Natural Gas Science and Engineering 52:507-14. doi:10.1016/j.jngse.2018.01.035.

Yu, W., G. Bo, and K. Sepehrnoori. 2014. Numerical study of the impact of complex fracture patterns on well performance in shale gas reservoirs. Journal of Petroleum Science Research 3 (2):83-89. doi:10.14355/ jpsr.2014.0302.05.

$\mathrm{Yu}, \mathrm{W}$., and K. Sepehrnoori. 2013. Optimization of multiple hydraulically fractured horizontal wells in unconventional gas reservoirs. Journal of Petroleum Engineering 2:1-16. doi:10.1155/2013/151898.

Yu, W., T. Zhang, D. Song, and K. Sepehrnoori. 2015. Numerical study of the effect of uneven proppant distribution between multiple fractures on shale gas well performance. Fuel 142:189-98. doi:10.1016/j.fuel.2014.10.074. 